Senge, M. O. (2015):

$\mathrm{N}-\mathrm{H}$ Hydrogen Bonding in Porphyrins - From Conformational Design to Supramolecular Chemistry. ECS Transactions 66, 1-10. doi: 10.1149/06616.0001ecst

\title{
N-H Hydrogen Bonding in Porphyrins - From Conformational Design to Supramolecular Chemistry
}

\author{
Mathias O. Senge
}

SFI Tetrapyrrole Laboratory, School of Chemistry, Trinity Biomedical Sciences Institute, 152-160 Pearse St., Trinity College Dublin, The University of Dublin, Dublin 2, Ireland

\begin{abstract}
Typically porphyrin N-H units are not involved in intermolecular hydrogen bonds as they are 'shielded' by the macrocycle system. However, two possibilities exist to utilize the pyrrole nitrogen atoms in such bonds: a) Porpho(di)methenes and phlorins (calixphyrin-type systems) contain $\mathrm{sp}^{3}$-hybridized meso positions and the interruption of the aromatic system gives rise to specific cavities and often roof- or bowl-shaped conformations making the core nitrogen and $\mathrm{N}-\mathrm{H}$ units more accessible for coordination. b) Likewise, saddle-distorted nonplanar porphyrins are very basic and can bind anions and neutral molecules via N-H hydrogen bonds in the core. Similarly, specific conformations and binding motifs can be accessed in porphyrin dications depending on the type, number, regiochemistry and steric bulk of substituents in the respective free base porphyrin. Here we give a brief overview of the different approaches and illustrate their use with regard to the design of ionpair receptors for small molecules and anions and the formation of potentially functional supramolecular complexes.
\end{abstract}

\section{Introduction}

Porphyrins are often discussed as macrocyclic compounds par excellence, especially due to their ability to chelate almost any metal in the core and the catalytic properties inherent to these metal complexes $\mathbf{1}$ (1). As a result, there is a rich coordination chemistry involving the central metals and/or peripheral substituents (2). In this context, the pyrrole $\mathrm{N}-\mathrm{H}$ units in the core in the so-called free base porphyrins 2 often appear in discussions solely as the precursor for metal insertion. They are thought of as "hidden" in the core and inaccessible for any meaningful use in supramolecular chemistry. Detailed studies of processes involving the N-H's have mostly been physical organic chemistry investigations of the $\mathrm{N}-\mathrm{H}$ tautomerism (3), i.e. studies on the behavior of the $\mathrm{N}-\mathrm{H}$ units within the porphyrin plane (Figure 1).

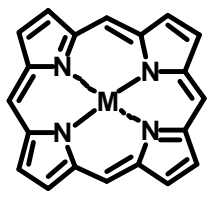

1

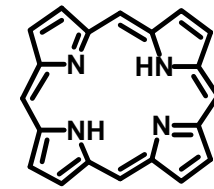

2

Figure 1. Metalloporphyrin, free base porphyrin and N-H arrangement in standard planar porphyrins (right). 
Being interested in the development of free base porphyrin receptors and catalysts we here explore the possibilities to construct and develop aromatic porphyrin systems where the pyrrole $\mathrm{N}-\mathrm{H}$ and imine units can participate directly in the formation or supramolecular complexes and/or be used as active sites in catalysts.

\section{Nonaromatic “porphyrinoids”}

Before looking at true porphyrins it must be noted that many porphyrin-type systems exist where pyrrole N-H units are used for the binding of other molecules or ions. This involves systems where conjugation through the meso bridges is interrupted, giving rise to macrocycles with isolated, individual pyrrole rings which are tilted out of the mean plane and accessible for reactions.

\section{Calixpyrroles and Calixphyrrins}

The classic example is Baeyer's acetonepyrrole, which contains four sp3 hybridized meso carbon atoms (4a). These compounds have been studied in much detail and many thousands of molecules and complexes have been prepared. Recall the transition metal complexes of calixpyrroles studies by Floriani and coworkers (4b) and the anion binding studies of Sessler, Gale and many others with compounds such as those shown in Figure $2(4 \mathrm{c}, 4 \mathrm{~d})$. These compounds are very stable and reoxidation to porphyrins is prevented by the presence of two substituents at the 'break' positions.

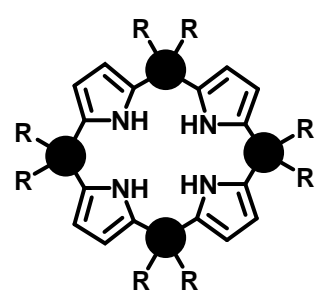

Calixpyrroles

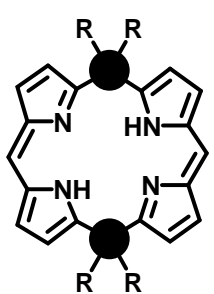

Calixphyrrins

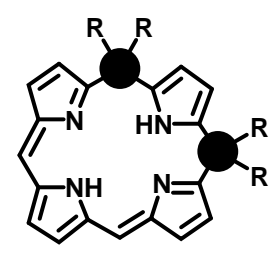

$=\mathrm{sp}^{3}$ hybridized, break in aromatic system
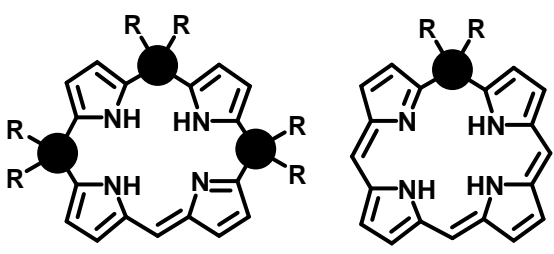

Figure 2. Nonaromatic tetrapyrrole receptors with $\mathrm{sp}^{3}$-hybridized meso carbon positions.

\section{Phlorins, Porphomethenes, Porphodimethenes and Porphyrinogens}

'Calix'systems similar to those shown in Figure 2 with $\mathrm{sp}^{3}$ hybridized -CHR- units can be formulated as well (Figure 3). These are more related to standard porphyrins; indeed, they are either (bio)synthetic precursors thereof or obtained as intermediates or side productions from substitution or reduction reactions. With increasing degree of macrocycle reduction these are the phlorins 7, porpho(di)methenes 4-6 and porphyrinogen 3. Again, many of these systems are known. As hydroporphyrins they are prone to oxidation to the porphyrin which limits their use as receptor materials. However, in several instances stable derivatives, which do not undergo oxidation - even under aerobic conditions - have been reported (5). 


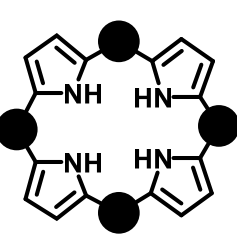

3

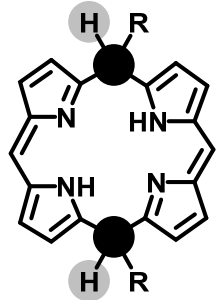

4

porphyrinogen

5,15-porphodimethene

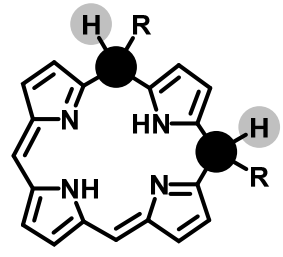

5

5,10-porphodimethene

$=\mathrm{sp}^{3}$ hybridized, break in aromatic system

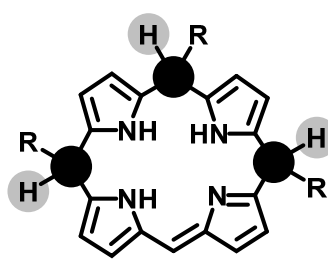

6

porphomethene

phlorin

Figure 3. Nonaromatic tetrapyrrole receptors with $\mathrm{sp}^{3}$-hybridized meso carbon positions.

Generally speaking two means exist to prepare such "oxidation-resistant" (meso) hydroporphyrins. One involves the use of sterically hindered aldehydes in pyrrole condensation or addition reactions, which can yield various types of porpho(di)methenes (6). Depending on the arrangement and type of meso substituents these give rise to different pattern of $\mathrm{N}-\mathrm{H}$ orientations in the macrocycles which indicates their potential as receptor materials. A typical example is shown in Figure 4. Here the use of pivaldehyde as a bulky aldehyde results in primarily nonaromatic tetrapyrrole condensation products which are locked in a stable conformation. While the exact product formation is difficult to control the products exhibit unique N-H orientations, e.g., two up one down ( $\uparrow \downarrow)$ in 8 and $\uparrow \uparrow$ in 9 .

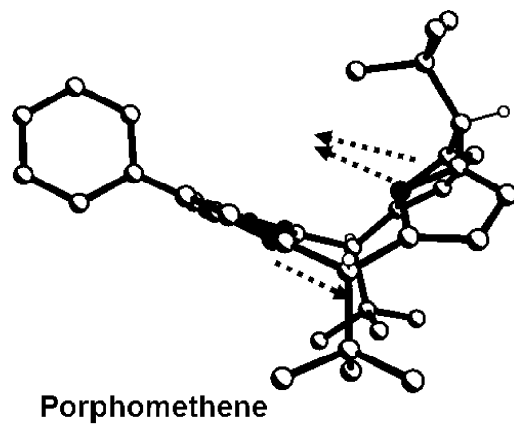

Figure 4. Porpho(di)methenes derived from pivaldehyde and pyrrole condensation reactions.

Secondly, meso hydroporphyrins can be generated via nucleophilic substitution of porphyrins (Figure 5) (7). Synthetically such reactions work best with metalloporphyrins giving rise to stable metalloporphodimethenes. However, demetallation of compounds such as $\mathbf{1 1}$ is difficult limiting their receptor potential (7d). Intriguingly, reaction with organolithium reagents in the presence of co-catalysts gives rise to 5,10-type free base porphodimethenes (8). The respective dications were more conjugated and showed increased stability and exhibited strong anion binding properties. In both cases the relative orientation of the large meso substituents, for example, a syn-diaxial orientation in 5,15-porphodimethenes, is key to their stability. 

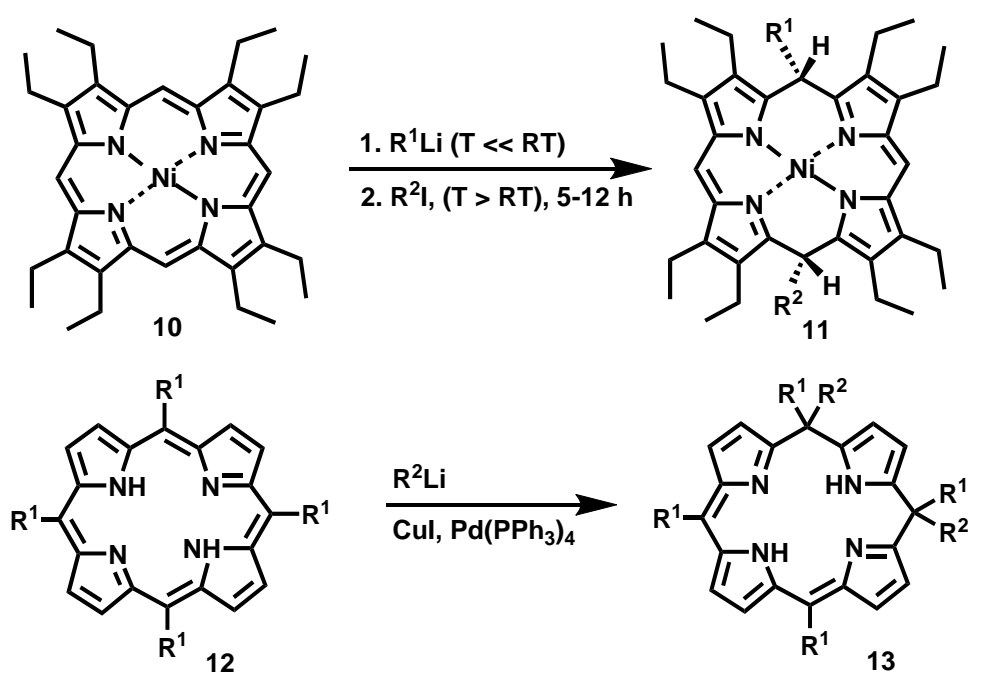

Figure 5. Preparation of porphodimethenes via reaction with organolithium reagents.

The various porphomethenes can easily be converted with acids to the respective salts. As indicated in Figure 6 for $\mathbf{1 5}$ the pyrroles are tilted significantly out of the mean plane (with $\uparrow \uparrow \downarrow \downarrow$ orientation) and participate in anion binding. Depending on the molecular geometry the meso hydrogen atoms can also participate in further stabilization of the salt structures (9).
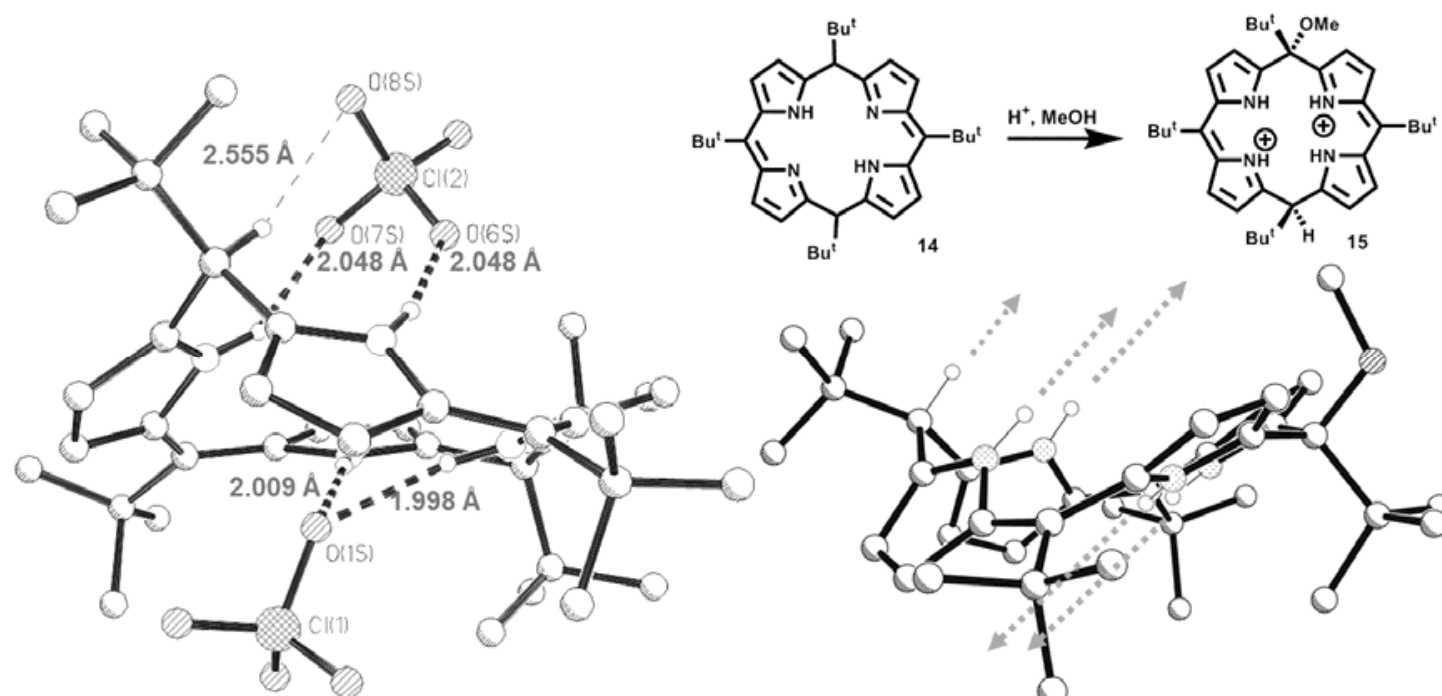

Figure 6. Preparation and view of the molecular structure of the diperchlorate salt of $\mathbf{1 5}$.

Nevertheless, all these calix-type compounds are not true porphyrins as they lack the conjugated tetrapyrrole system and thus lack the unique photophysical and chemical properties of porphyrins.

\section{Accessing N-H in Porphyrins}

The use of free base porphyrins for N-H binding of substrates requires the $\mathrm{N}-\mathrm{H}$ to be accessible, i.e. they must be tilted out of the plane of macrocycle as illustrated in Figure 7. 
This would retain the aromatic character of the macrocycle, retain the porphyrin function as a chromophore and enable new functions as a receptor.

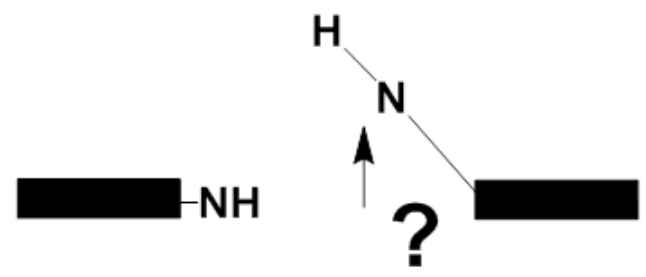

Figure 7. Accessing pyrrole N-H via out of plane distortion.

\section{Porphyrin Dications}

Two means exist to achieve such a goal. First, one can 'force' the formation of desired products by use of direct reactions with the pyrrole nitrogen atoms. Examples are the formation of $\mathrm{N}$-alkylated or arylated compounds (10) which may yield separated ion pairs (10b) or protonation to yield the respective porphyrin (di)cations. Going back to the early studies by Fleischer this is an established field whereby steric overcrowding in the porphyrin care, either by the presence of four hydrogen atoms or organic residues, results in the formation of highly nonplanar porphyrins where the imine and/or pyrrole nitrogen units can participate in hydrogen bonding with the counter anions (11). This give rise to various crystal packing motifs including highly ordered supramolecular structures. Two typical examples are shown in Figure 8.
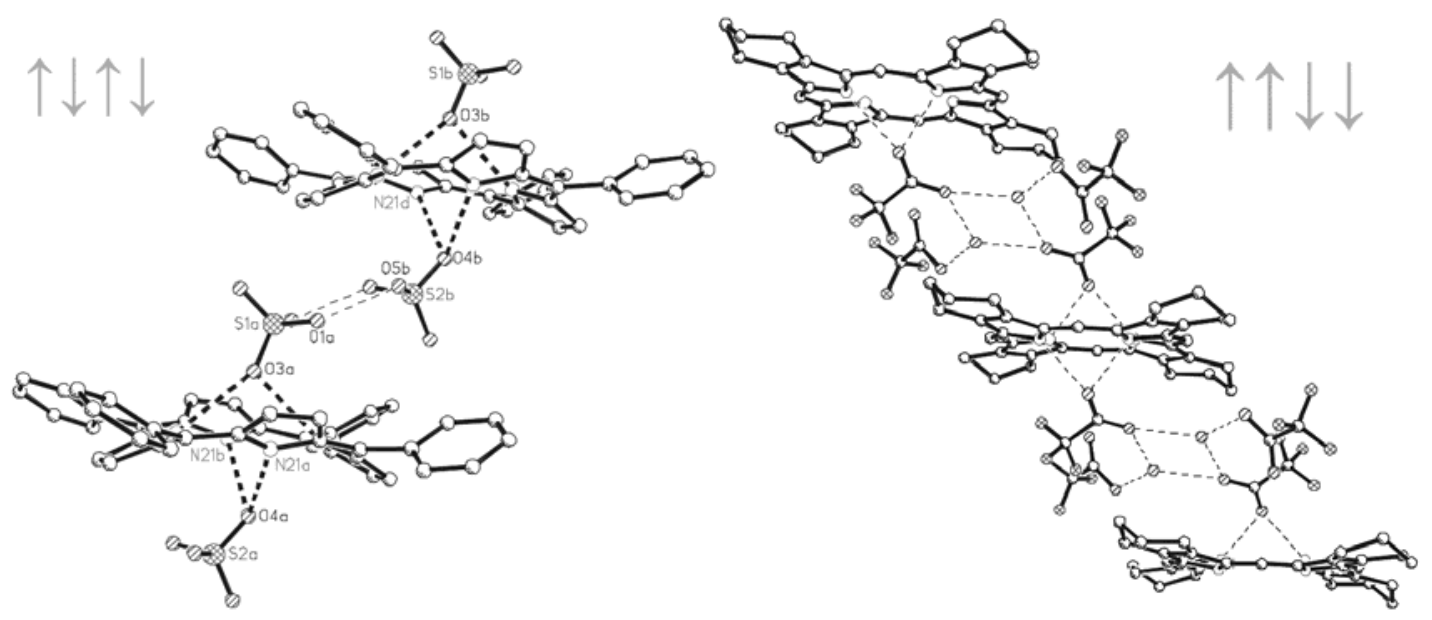

Figure 8. View of hydrogen bonding pattern in the crystal structures of $\left\{\left[\mathrm{H}_{4} \mathrm{TPP}\right]\left[\mathrm{HSO}_{4}\right]_{2}\right\}_{\mathrm{n}}$ (left) and $\left\{\left[\mathrm{H}_{4} \mathrm{TCHP}\right]\left[\mathrm{F}_{3} \mathrm{CCO}_{2}\right]_{2} \cdot 2 \mathrm{CF}_{3} \mathrm{CO}_{2} \mathrm{H} \cdot 2 \mathrm{H}_{2} \mathrm{O}\right\}_{\mathrm{n}}$ (right). TPP = 5,10,15,20-tetraphenylporphyrinato; TCHP $=2: 3,7: 8,12: 13,17: 18$-tetracyclohexenoporphyrinato.

In most cases protonation results in the formation of saddle distorted porphyrins with alternating up and down tilting $(\uparrow \downarrow \uparrow \downarrow)$ of the pyrrole units. Nevertheless, in individual cases, for example some 2,3,7,8,12,13,17,18-octaalkylporphyrins, different $\mathrm{N}-\mathrm{H}$ orientations $(\uparrow \uparrow \downarrow \downarrow)$ have been observed (12). Still, while anion binding in such salts is of interest and can be of interest for the development of nonlinear optical materials (13) we are ultimately interested in the use of neutral free base porphyrins as receptors and 
catalysts. As illustrated in Figure 7, this requires a nonplanar macrocycle with accessible $\mathrm{N}-\mathrm{H}$. Thus, the question arises how to distort the porphyrin macrocycle while retaining (most) of its characteristics properties. This second approach relies on a modulation of the macrocycle conformation.

\section{Nature's Way - Chelatases}

As so often, nature can provide an answer to this. For a long time it was surmised that the natural chelatase enzymes, which incorporate metals into porphyrins, functions by first distorting the macrocycle and then inserting the metal ion. In line with this hypothesis nonplanar $\mathrm{N}$-alkylated porphyrins were found to be inhibitors of ferrochelatase and more recently this mechanism was confirmed with protein crystallographic studies (Figure 9) (14).

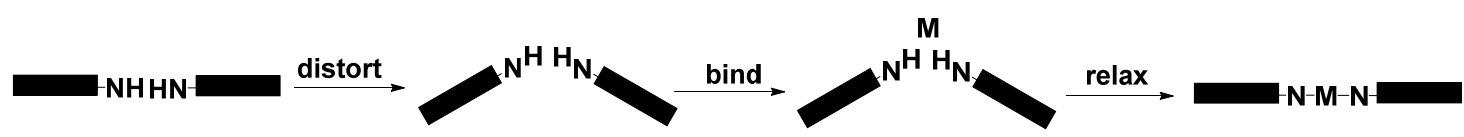

Figure 9. Schematic illustration of the mechanism of chelatases.

\section{$\underline{\text { Highly Substituted, Nonplanar Porphyrins }}$}

On the other hand the use of highly substituted nonplanar porphyrins has been an active field of porphyrin research for more than three decades (5). Here peripheral peri interactions are used to induce steric strain whereby the porphyrin macrocycle becomes nonplanar. There are several approaches to prepare nonplanar porphyrins which include sterically overloading the periphery of porphyrin, metal and axial ligand effects, core manipulation, strapping and others. Many possibilities have been tested with notable success and showed that nonplanar porphyrins can easily be prepared and demonstrate altered chemistry (higher basicity, oxidation resistance, novel substitution reactions), electrochemistry (easier to oxidize), photophysics (very low fluorescence yields and short excited state lifetimes via acceleration of the radiationless deactivation processes), and different peripheral substituents give rise to different conformations (out-of-plane distortions: ruffled, domed, wave, saddle, propeller and in-plane distortions) $(15,16)$.

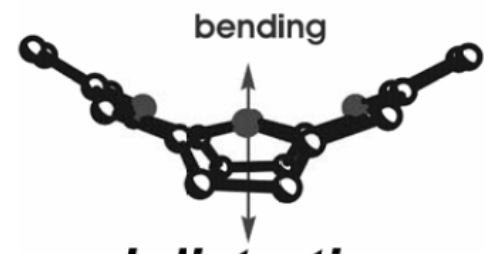

sad distortion<smiles>CN</smiles><smiles>CN</smiles>

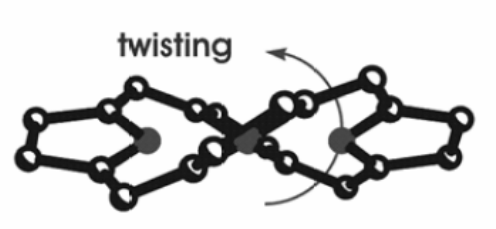

ruf distortion

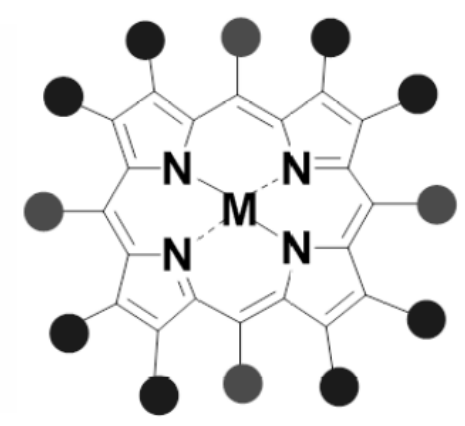

$$
-\mathrm{N}-\mathrm{H} \text { H-N- }
$$

Figure 10. Illustration of the two main means of pyrrole manipulation in highly substituted porphyrins. 
In the context of the present discussion a closer look must be taken at the various distortion types. With regard to the pyrrole units - somewhat simplified - two different types can be observed. Either the pyrrole rings are tilted upwards and downwards out of the macrocycle plane (predominantly observed in saddle distorted systems) or they are rotated about the $\mathrm{N}-\mathrm{C}_{\mathrm{b}}-\mathrm{C}_{\mathrm{b}}$ axis. The latter is mostly found in ruf distorted systems and here the $\mathrm{N}-\mathrm{H}$ units remain in the plane of the macrocycle $(9,17)$. The two different situations are illustrated in Figure 10.

The saddle distorted porphyrins are very similar in conformation to the one observed in most porphyrin dications. Thus, the N-H are tilted outwards from the core and are now directly accessible. Not surprisingly, they now participate in hydrogen bonding and allow a binding of small molecules in the cavities formed by the nonplanar macrocycle and its substituents. A typical example is that of 2,3,5,7,8,10,12,13,15,17,18,20dodecaphenylporphyrin (18), which, for example can bind ethanol molecules via hydrogen bonding in the core (Figure 11) (18b). Other examples are the coordination of chlorinated solvent molecules to the imine nitrogen atoms in saddle distorted porphyrins (19).
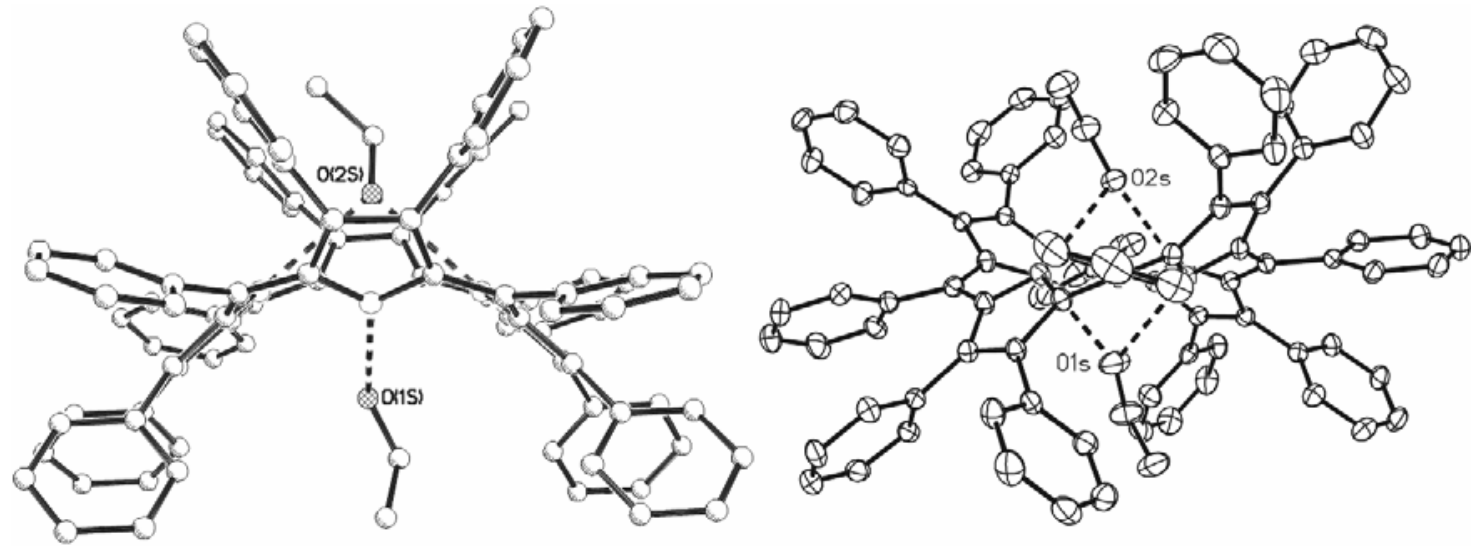

Figure 11. Two different views of the hydrogen bonding in a diethanol solvate of 2,3,5,7,8,10,12,13,15,17,18,20-dodecaphenylporphyrin.

Naturally, nonplanar porphyrins can also be converted into the respective porphyrin salts and N-substituted derivatives $(10 \mathrm{~b}, 11 \mathrm{~b}, \mathrm{c})$ which exhibit increased degrees of nonplanarity. For example, the free base 2,3,7,8,12,13,17,18-octaethyl-5,10,15,20tetraphenylporphyrin exhibits an average deviation of the 24 macrocycle atoms from their least-squares plane of $0.54 \AA$ which increases upon dication formation to 0.61-0.64 $\AA$, depending on the counter anion (12). These reactions proceed much faster with the respective saddle distorted systems, while ruffled porphyrins tend to undergo side reactions under disruption of the aromatic system $(9,17 \mathrm{a})$. Nevertheless, careful protonation of free base ruffled porphyrins under argon results in the formation of porphyrin dications with predominantly saddle distorted macrocycles (12b) (Figure 12). 

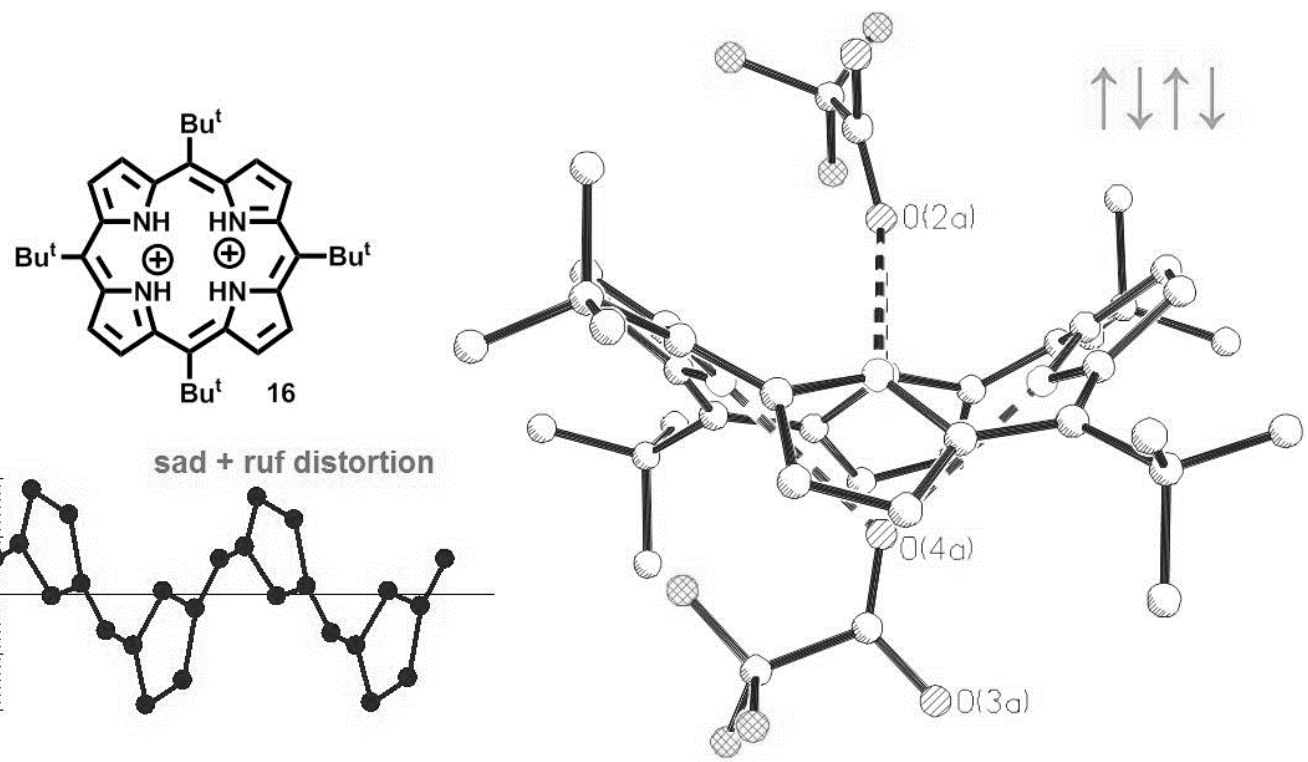

Figure 12. View of the hydrogen bonding and skeletal deviations in the crystal structure of $\left[\mathrm{H}_{4} \mathrm{TtBuP}\right]\left[\mathrm{CF}_{3} \mathrm{COOH}\right]_{2}$.

\section{Free Base Porphyrins as Catalysts?}

Finally, the question arises whether systems as those outlined above can be used as catalysts where the N-H units participate as active units in the catalytic reaction? Clearly, the N-H units can be made more accessible by macrocycle distortion. Indeed, the outwards orientation of the N-H vector can be modulated gradually depending on the degree of peripheral substitution. This is illustrated in Table 1, where a series of 5,10,15,20-tetraphenylporphyrins with increasing number of $\beta$-ethyl groups (17-22) exhibits a concomitant increase in out of plane tilting of the (pyrrole) $\mathrm{N}-\mathrm{H}$ units (19).
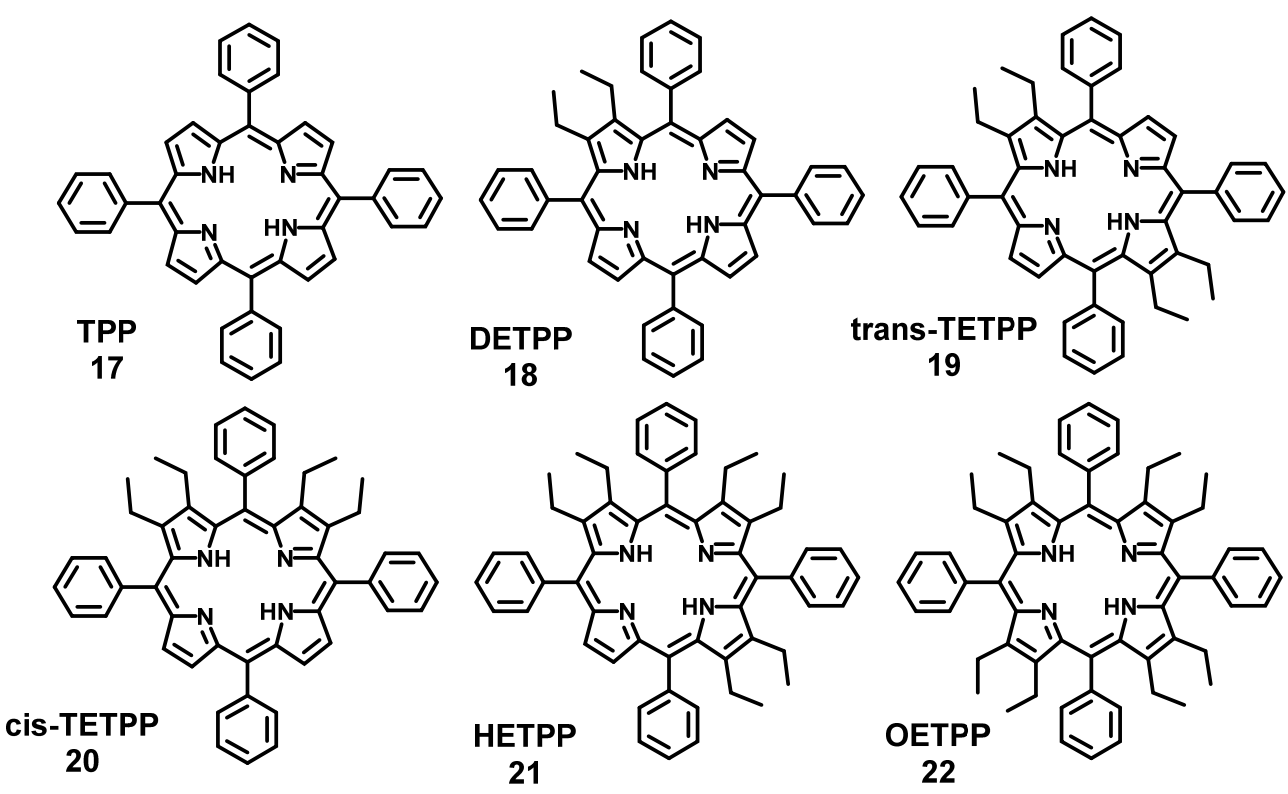
Table 1. Pyrrole tilt angles in the XEtTPP series of porphyrins 17-22.

\begin{tabular}{lccccccr}
\hline Compound & $\Delta \mathbf{2 4}^{\mathbf{a}}$ & \multicolumn{7}{c}{ Pyrrole tilt, deg } \\
& & \multicolumn{7}{c}{ Quadrant } \\
& & average & $\mathbf{N 2 1}$ & $\mathbf{N 2 2}$ & $\mathbf{N 2 3}$ & $\mathbf{N 2 4}$ \\
\hline OEP & 0.02 & 1.7 & 2.2 & 1.1 & $*$ & $*$ \\
TPP, triclinic & 0.05 & 4.0 & 6.6 & 1.4 & $*$ & $*$ \\
TPP, tetragonal & 0.19 & 11.9 & 11.9 & $*$ & $*$ & $*$ \\
DETPP & 0.10 & 4.3 & 6.8 & 0.5 & 3.1 & 6.7 \\
tTETPP & 0.29 & 15.0 & 16.3 & 14.1 & 15.9 & 13.7 \\
cTETPP & 0.38 & 20.4 & 25.1 & 33.7 & 14.8 & 7.8 \\
HETPP & 0.46 & 24.0 & 20.3 & 29.0 & 28.6 & 17.9 \\
OETPP & 0.54 & 31.2 & 26.7 & 34.8 & 33.5 & 29.7 \\
\hline \multicolumn{7}{c}{${ }^{a}$ Average deviation from the 24-atom macrocycle plane. }
\end{tabular}

In terms of chemical reactivity the most intriguing aspect of saddle distorted porphyrins is their significantly increased basicity (20). Dodecasubstituted porphyrins can easily be protonated by water and their metalation kinetics are several orders of magnitude larger than those of planar porphyrins $(21,22)$. Further modulation of the core reactivity can be achieved by electronic modulation of the peripheral substituents. In a sense the core of a free base porphyrin can be considered as bifunctional system where the imine units can be used for nucleophilic activation and the pyrrole N-H units for electrophilic activation. This opens the possibility to use conformational design to prepare tailor made porphyrins with specific binding and receptor functions.

\section{Acknowledgments}

Our recent work in this area was supported by a grant from Science Foundation Ireland (SFI IvP 13/IA/1894 SFI).

\section{References}

1. (a) J. W. Buchler, in The Porphyrins, D. Dolphin, Editor, Vol. 1, pp. 289, Academic Press, New York, USA (1978); (b) D. Mansuy, Compt. Rend. Chim., 10, 392 (2007).

2. I. Beletskaya, V. S. Tyurin, A. Y. Tsivadze, R. Guilard, C. Stern, Chem. Rev., 109, 1659 (2009).

3. (a) B. Wehrle, H. H. Limbach, M. Kocher, O. Ermer, E. Vogel, Angew. Chem. Int. Ed. Engl., 26, 934 (1987); (b) P. Wacker, K. Dahms, M. O. Senge, E. Kleinpeter, J. Org. Chem., 73, 2182 (2008).

4. (a) A. Baeyer, Ber. Dtsch. Chem. Ges., 19, 2184 (1886); (b) C. Floriani, R. Floriani-Moro, Adv. Organomet. Chem., 47, 167 (2001); (c) D. S. Kim, J. L. Sessler, Chem. Soc. Rev., 44, 532 (2015); (d) J. L. Sessler, S. Camiolo, P. A. Gale, Coord. Chem. Rev., 240, 17 (2003).

5. M. O. Senge, Chem. Commun., 243 (2006). 
6. (a) S. Runge, M. O. Senge, Z. Naturforsch., 53b, 1021 (1998); (b) M. O. Senge, S. Runge, M. Speck, K. Ruhlandt-Senge, Tetrahedron, 56, 8927 (2000).

7. (a) W. W. Kalisch, M. O. Senge, Angew. Chem. Int. Ed., 37, 1107 (1998); (b) B. Krattinger, H. J. Callot, Eur. J. Org. Chem., 1857 (1999); (c) M. O. Senge, Acc. Chem. Res., 38, 733 (2005); (d) I. Bischoff, X. Feng and M. O. Senge, Tetrahedron, 57, 5573 (2001).

8. (a) N. N. Sergeeva, Y. M. Shaker, E. M. Finnigan, T. McCabe, M. O. Senge, Tetrahedron, 63, 12454 (2007); (b) E. M. Finnigan, S. Giordani, M. O. Senge, T. McCabe, J. Phys. Chem. A, 114, 2464 (2010).

9. T. Ema, M. O. Senge, N. Y. Nelson, H. Ogoshi, K. M. Smith, Angew. Chem., Int. Ed. Engl., 33, 1879 (1994).

10. (a) D. K. Lavallee, The Chemistry and Biochemistry of N-Substituted Porphyrins, VCH, Weinheim (1987); (b) M. O. Senge, W. W. Kalisch, S. Runge, Liebigs Ann., 1345 (1997).

11. (a) A. Stone, E. B. Fleischer, J. Am. Chem. Soc., 90, 2735 (1968); (b) M. O. Senge, T. P. Forsyth, L. T. Nguyen, K. M. Smith, Angew. Chem., Int. Ed. Engl., 33, 2485 (1994); (c) B. Cheng, O. Q. Munro, H. M. Marques, W. R. Scheidt, J. Am. Chem. Soc., 119, 10732 (1997); (d) M. Presselt, W. Dehaen, W. Maes, A. Klamt, T. Martinez, W. J. D. Beenken, M. Kruk, Phys. Chem. Chem. Phys., 17, 14096 (2015).

12. (a) M. O. Senge, W. W. Kalisch, Z. Naturforsch., 54b, 943 (1999); (b) M. O. Senge, Z. Naturforsch., 55b, 336 (2000).

13. M. Zawadzka, J. Wang, W. J. Blau, M. O. Senge, J. Porphyrins Phthalocyanines, 17, 1129 (2013).

14. (a) S. Al-Karadaghi, R. Franco, M. Hansson, J. A. Shelnutt, G. Isaya, G. C. Ferreira, Trends Biochem. Sci., 31, 135 (2006); (b) A. Medlock L. Swartz, T. A. Dailey, H. A. Dailey, W. N. Lanzilotta, Proc. Natl. Acad. Sci. U.S.A., 104, 1789 (2007).

15. M. O. Senge, in The Porphyrin Handbook, K. M. Kadish, K. M. Smith, R. Guilard, Editors, Vol. 1, p. 239, Academic Press, San Diego, (2000).

16. M. O. Senge, in The Porphyrin Handbook, K. M. Kadish, K. M. Smith, R. Guilard, Editors, Vol. 10, p. 1, Academic Press, San Diego, (2000).

17. (a) M. O. Senge, I. Bischoff, N. Y. Nelson, K. M. Smith, J. Porphyrins Phthalocyanines, 3, 99 (1999); (b) D. L. Cullen, L. V. Desai, J. A. Shelnutt, M. Zimmer, Struct. Chem., 12, 127 (2001).

18. (a) C. J. Medforth, M. O. Senge, K. M. Smith, L. D. Sparks, J. A. Shelnutt, J. Am. Chem. Soc., 114, 9859 (1992); (b) M. O. Senge, Z. Naturforsch., 54b, 821 (1999).

19. (a) W. W. Kalisch, M. O. Senge, Tetrahedron Lett., 37, 1183 (1996); (b) M. O. Senge, W. W. Kalisch, Inorg. Chem., 36, 6103 (1997).

20. A. Neuberger, J. J. Scott, Proc. Roy. Soc. London, Ser. A, 213, 307 (1952).

21. O. S. Finikova, A. V. Cheprakov, P. J. Carroll, S. Dalosto, S. A. Vinogradov, Inorg. Chem., 41, 6944 (2002).

22. P. Bhyrappa, M. Nethaji, V. Krishnan, Chem. Lett., 22, 869 (1993). 